INTERNATIONAL DESIGN CONFERENCE - DESIGN 2018

https://doi.org/10.21278/idc.2018.0322

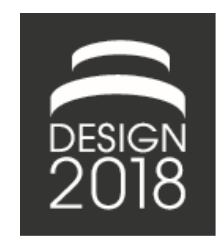

\title{
ANALYZING RID METHODOLOGY THROUGH THE LENS OF INNOVATIVE ABDUCTION
}

\author{
G. Lamé, B. Yannou and F. Cluzel
}

\begin{abstract}
The literature reports that abduction is inherent to design reasoning. The Radical Innovation Design methodology is analyzed using the lens of Kroll and Koskela's two-step innovative abduction. In the first phase (Problem Setting), the Knowledge Design process follows a two-step selective abduction and the Problem Design process comprises abduction followed by deduction. This illustrates the specific reasoning employed when identifying the right problem on which to innovate. In the second phase (Problem Solving), the reasoning follows two-step innovative abduction.
\end{abstract}

Keywords: abductive reasoning, radical innovation design, innovation management, design methodology, design theory

\section{Introduction}

Innovation is at the heart of today's business considerations (Christensen, 1997). To innovate, companies look for methods and processes that they can apply. One such proposition is the Radical Innovation Design (RID) methodology (Yannou, 2015). RID is based on different established principles and theories in innovation and design management, e.g. stage-gate processes (Cooper, 1990), set-based design (Sobek et al., 1999), the creation of new usage spaces as in Blue Ocean Strategy (Kim and Mauborgne, 2015) or need-seeker and jobs-to-be-done innovation (Jaruzelski et al., 2014; Christensen et al., 2016).

In the past ten years, RID has been applied on a variety of industrial projects. To improve our understanding of the methodology, we now wish to compare the way design proceeds in RID with formal models of design reasoning. Different such models exist; for instance, the Function-BehaviourStructure framework (Gero and Kannengiesser, 2004), C-K theory (Hatchuel and Weil, 2009) or abductive design (Kroll and Koskela, 2016).

In these analysis, we first want to assess how RID fits in a given framework, by mapping the concepts and processes of RID to those proposed by this formalism. In so doing, we wish to explore how formal models of design can help illuminate the embedded mechanisms that help RID support innovative design, and to identify potential specificities of RID. In a second stage, we could then use these analyses to improve RID. In the past, such approaches have yielded interesting insights on methods such as ASIT (Reich et al., 2012).

This article reports a first initiative in this research programme. We analyse RID using the theoretical lens of Kroll and Koskela's two-step innovative abduction (Kroll and Koskela, 2016). This model describes design reasoning as a double abduction from a desired function to a concept, and from this concept to a suitable form. Using this framework, we expect to deepen our understanding of the way RID supports value creation through innovative design and the generation of new knowledge and concepts adapted to users first and markets hereafter. Reciprocally, the analysis of a practical innovation 
method can shed light on the validity of two-step innovative abduction in describing innovative design processes, and enrich this theoretical perspective.

To put this research program to work, we first describe Kroll and Koskela's model of two-step innovative abduction (Section 2). We then present the RID methodology's principles and processes (Section 3). We then proceed to compare and map the concepts of RID and two-step innovative abduction (Section 4.1), and to map the RID process in the framework of two-step innovative abduction (Sections 4.2 and 4.3).

\section{Abduction in design}

\subsection{Abductive reasoning}

Table 1, adapted from Dorst (2011) and Kroll and Koskela (2016), shows the different types of logical reasoning. There are four main patterns:

- In deduction, a precondition and a rule are known, from which conclusions are inferred.

- In induction, repeated observations of the coexistence of a precondition and a conclusion lead to infer a rule.

- In selective abduction, a conclusion and a rule are known, from which a plausible precondition is inferred.

- In creative abduction, only the conclusion is known, and both the rule and the precondition must be inferred.

Selective abduction is the main process in routine design: designers know a set of working principles among which they choose to solve a given problem. Creative abduction is used when no known rule can provide the desired conclusion. This is the way of innovative design (Dorst, 2011; Kroll and Koskela, 2016). Characterizing where and how abductive reasoning operates in RID methodology might allow to precisely compare a RID process to the conventional innovation process described in (Kroll and Koskela, 2016), see also Figure 1.

Table 1. Different types of logical reasoning

\begin{tabular}{llllll} 
Precondition & & Rule & & Conclusion & Type of reasoning \\
\hline Precondition & + & Rule & $=$ & $?$ & Deduction \\
\hline Precondition & + & $?$ & $=$ & Conclusion & Induction \\
\hline$?$ & + & Rule & $=$ & Conclusion & Selective abduction \\
\hline$?$ & + & $?$ & $=$ & Conclusion & Innovative abduction
\end{tabular}

\subsection{Application of abductive reasoning to design}

At the beginning of a design project, designers wish to accomplish something, for which they have to design a means. They have to infer to a suitable product that can help them reaching their objective. This mirrors abductive reasoning: only the outcome (the objective) is known. Based on this, authors have argued that the main mode of reasoning in design science is abduction (Cross, 1982; Dorst, 2011; Kroll and Koskela, 2016). Different models have been proposed, using the three constructs presented above (precondition, rule and conclusion), sometimes labelled differently. For instance, Dorst argues that designers start from an aspired value (the conclusion), that based on their knowledge they infer a suitable working principle (the rule), and that finally, they will propose an object (precondition) which can produce this working principle, to deliver the aspired value.

In a recent paper, Kroll and Koskela (2016) review Dorst's model and other previous contributions on abduction in design. They identify several logical shortcomings and propose a new model. To represent abductive reasoning in design, they argue that four constructs are needed: function, way of use, mode of action, and form.

- Function is "a desired result or purpose". It represents value creation.

- Way of use is the procedure to use a given artefact. It describes a "standard operating procedure" under which the artefact should produce the desired function. 
- Mode of action is the way in which the system is "using laws of nature to produce a desired effect". It refers to the set of mechanisms that produces the desired function when using an artefact following a specified way of use.

- Form is an artefact, which is designed to, when used according to the planned way of use, enact the mechanisms of its mode of action to produce the desired function.

One can notice that the "rule" of Table 1 has been further developed into a "way of use" and "mode of action". This is because a single concept could not capture both of these notions, and struggled to explain even simple design examples, has shown by Kroll and Koskela (2016). The authors then show that design proceeds in two steps. First, from a desired function, designers infer the pair "way of use + mode of action". Then, from that pair designers infer a form that can generate it. The authors label this process "two-step innovative abduction". Figure 1 represents this process.

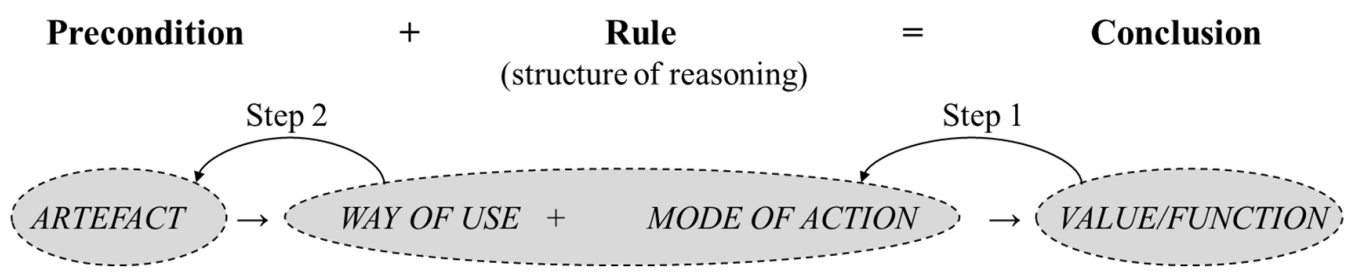

Figure 1. Our representation of Kroll and Koskela's two-step innovative abduction model

\section{The Radical Innovation Design (RID) methodology}

\subsection{Foundations and principles}

Different theoretical streams were influential in the development and evolution of RID (Yannou, 2015):

- Set-based concurrent engineering (Sobek et al., 1999), with the principle of waiting to make decisions to keep different options open, and to consider sets of artefacts corresponding to sets of functions/values.

- Need-seeker innovation (Jaruzelski et al., 2014), the idea that rather than looking for technological breakthroughs and pushing them on consumers (techno-push innovation), designers can pull products from thorough analysis of the behaviour and problems met by users. Need seeker innovation goes primarily from expected functions/values to artefact solutions, whereas Techno driver innovation primarily starts from artefact technologies to further identify useful applications.

- Christensen's concepts of disruptive innovation and jobs-to-be-done (Christensen, 1997; Christensen et al., 2016) for which providing a new solution to users (customers) allowing them to better doing their job is the most determining guarantee for being successful and innovation leader.

- Kim and Mauborgne's Blue Ocean Strategy (2015) and the two principles of addressing nonusers' needs and focusing on novel or neglected offer attributes (blue oceans) instead of fighting with competitors on the same offer attributes (red oceans), so as to shift the competition.

- Cooper's stage-and-gate system (1990), which supports processes with periodic design reviews where projects are assessed, and only allowed to continue if they have sufficient potential.

RID has been developed iteratively, through applications to industrial student projects, e.g. (Yannou et al., 2013a; Bekhradi et al., 2017; Lamé et al., 2018), and through more theoretical research on usagedriven design, e.g. (Yannou et al., 2013b; Bekhradi et al., 2015). We now present RID's process.

\subsection{The RID process}

RID has two main stages, and four sub-processes: Problem Design and Knowledge Design in the first Problem setting stage, and Solution Design and Business Design in the second Problem Solving stage. The whole process is represented in Figure 2. 


\subsubsection{Problem Design stage}

The RID process does not start with a specific function to perform, since RID considers that setting the design problem is already a design task. In real life, designers start from an initial idea, which can be an existing concept to upgrade or outperform ("a system with these characteristics"), an idea of solution or an idea of problem - an intuition that "there is something to be done in this area" -, or even a company injunction to innovate in a given business line where margins are dropping. The designers then transform the initial idea into a set of \{activity fields + ideal goal\}, the activity fields referring to a homogeneous class of users - RID speaks of value beneficiaries - and ideal goal referring globally to the expected value creation behind the initial idea. This ideal goal is expressed in functional terms ("a system that allows..."). It is generally much broader than the initial idea; it is expressed in reference to the sole users, i.e. direct value beneficiaries, rather than as future profits or increased competitiveness for the company.

Next, inside the activity fields, designers investigate what RID calls deep knowledge - by the Knowledge design sub-process - and result in a set of typical usage situations that users live and during which they are not totally satisfied with their jobs-to-be-done. Here, designers do not directly express sets of objectives; instead they come up after investigation with:

- A typology of usage situations;

- A typology of problems experienced by users in these situations;

- A causal map of the mechanisms that create these problems; and

- A typology of existing solutions that can alleviate (at least partly) the problems identified.

Usage situations are combinations of user and situational characteristics (Bekhradi et al., 2015). Inside usage situations, scenarios represent typical unfolding of events as comic strips or text narratives, in order to illustrate the problems and to communicate through the use of fictitious personas. Problems are issues or lacks of performance experimented by users, sometimes called "pains" in marketing. They can be consciously expressed, but it also occurs that they have been internalized as "the way things work" and have to be uncovered by designers. Sketching causal maps (graphs) leads to uncover the various interacting causes of problems. In RID, "existing solutions" are classes of current products or services which may avoid or diminish the effects of one or several problems during one or several usage situations. A graphical mapping of the influence of all classes of existing solutions onto the causal map is carried out. Doing so, it is easy to detect zones where problems are not covered or existing solutions which would merit to be hybridize as they cover distinct zones.

Thanks to an algorithm, DSM Value Bucket (Yannou et al., 2016), the information on usage situations, problems and existing solutions is combined and processed in order to identify the situations where existing solutions are least effective at reducing problems. These (usage situation, problem) pairs are called value buckets. What happens here is a reduction of the activity fields as an interesting ground to innovate. All areas where existing solutions perform well are eliminated, and the designers focus on areas where important issues occurring in frequent usage situations remain to be solved. Finally, designers use a Kano customer survey (Matzler et al., 1996) to compromise the identified value buckets with the most notable customers' desires and result in a perimeter of ambition.

Through this process, at the end of the Problem Design stage, designers define an ambition perimeter, containing a few selected value buckets where the value gap is high between the problems users experience and the performance of existing solutions, and which customers acknowledge as desirable in the Kano survey. This means that at this stage, we have:

- A well-defined set of usage situations, in which

- Problems have been identified that will be the target of future design stages.

The designers have also identified:

- The causal mechanisms that create these problems in these situations;

- The shortcomings of existing solutions;

- The way users routinely interact with existing solutions, and the way they manage problems experienced by users in the design perimeter. 


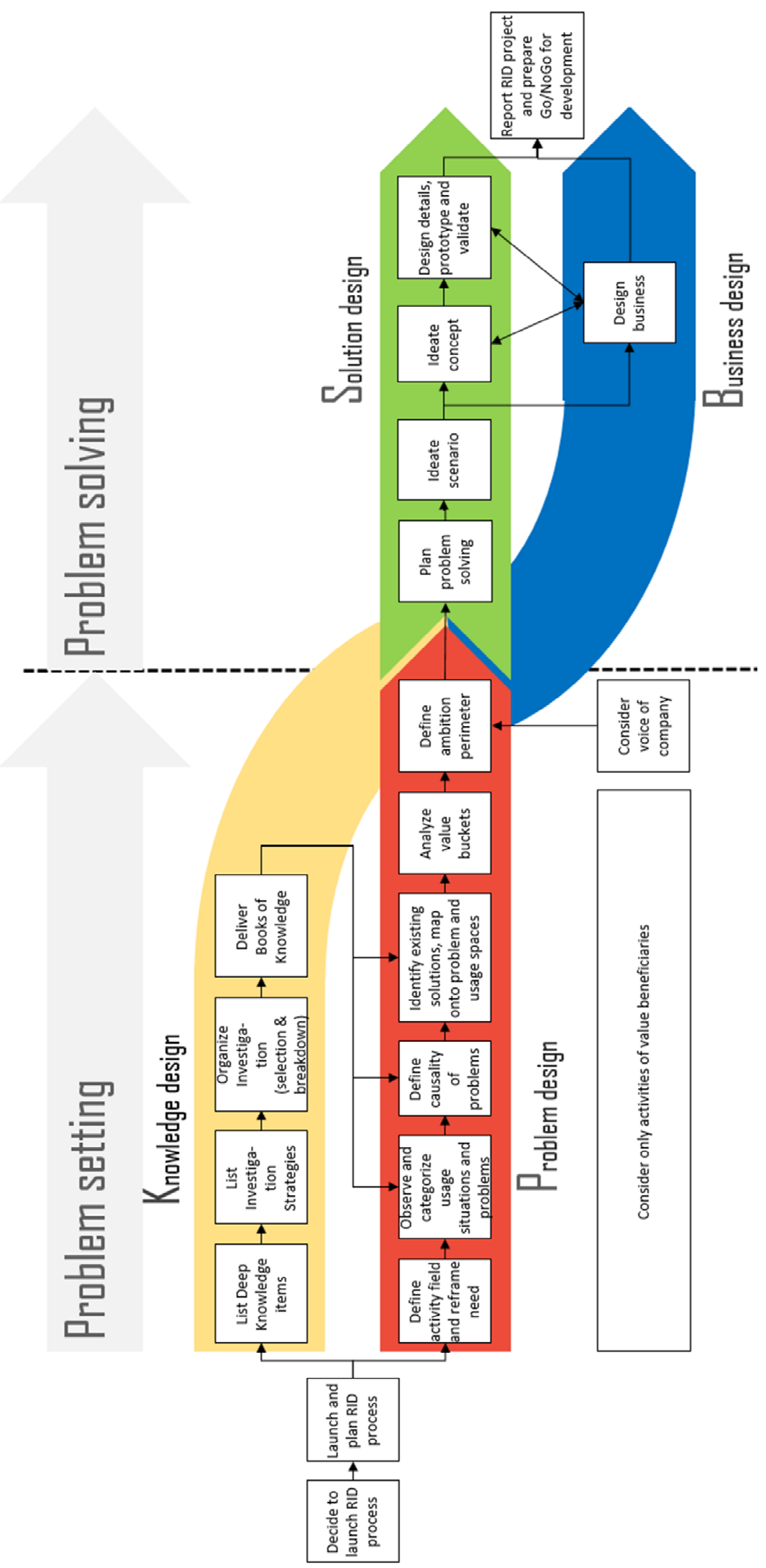

Figure 2. Representation of the RID process 


\subsubsection{Knowledge Design}

Designers need to gather a lot of data to feed the Problem Design. The objective is to quickly identify relevant information and knowledge that applies to the activity fields. Designers use multiple methods, such as empirical investigation through ethnographic observation, interviews and questionnaires, or literature review.

The Knowledge Design process proceeds as follows. First, designers brainstorm on potential areas of interest inside the activity fields that stem from the initial idea. From the list of potential topics, they work to extract deep knowledge required for their project, i.e. areas of expertise that they need to acquire through various investigation strategies, e.g. readings, interviewing experts or generating their own empirical data through observations and interviews. Next, they must plan the investigation (allocate tasks to project members, define schedule). All the knowledge gathered during the investigation is synthesised in books of knowledge, which constitute valuable repositories for the present project but also for future projects in the company.

The challenge in the knowledge design process is not only to identify important knowledge for the project, but also to synthesise it in a way that can easily be shared and re-used. Good, effective books of knowledge are often highly visual, using concept maps, pictures and graphs to represent important concepts and their relationships. Books of knowledge contain information on different dimensions of the design problem. For instance, they may list interesting mechanisms for tackling elements of the problem, information on users' expectations and issues, reflections on how functionally close problems have been overcome in other areas, or models (physical, chemical, psychological...) of the underlying causal mechanisms generating the problems.

\subsubsection{Solution Design stage}

The solution design stage starts with the ambition perimeter defined above. The first stage is scenario creativity. Starting from the ambition perimeter, which defines pairs of usage situations and problems to be addressed, designers propose one or several usage scenarios, i.e. sequence of events where a yet undefined solution intervenes that can solve the aforementioned problems. They can use all forms of creativity methods (e.g. brainstorming or thinking hats).

Then, designers organise a "concept creativity" session. Using creativity methods, they come up with principles that can perform the desired functions in the scenario(s) identified before. RID specifies that knowledge gathering mainly happens during the Problem Design stage, so at this stage, in principle, designers should mainly build on the knowledge accumulated before. The principles identified during Knowledge Design can be enriched, combined and integrated in new ways to perform the required functions. Empirical investigations should mainly be focused on testing the concept through contacting potential users and producing prototypes. In the end, designers come up with a concept that assembles principles (new or known) in novel ways to produce, in the envisioned usage scenarios, the value contained in the ambition perimeter.

Finally, based on the concept and the usage scenarios, designers can proceed to detailed design, validation and prototyping.

\subsubsection{Business Model Design}

In parallel to the Solution Design stage, designers design and refine the business model of the system. This activity is based on Osterwalder and Pigneur's Business Model Canvas (2010), which has been enriched to initiate the canvas in "Value Proposition" and "Customer segmentation" boxes from highly rated value buckets (Bekhradi et al., 2016). The objective is to ensure that the new product or service is supported by the right infrastructure (suppliers, production, distribution, and marketing) and that it can generate sufficient revenue.

\section{Discussion}

We have presented two-step innovative abduction and the RID process. We now try to match the two to see if RID can help designers perform two-step innovative abduction. We follow RID's two phases, Problem setting (Knowledge design and Problem design) and Problem solving (Solution design and 
Business design), and analyse both in terms of Kroll and Koskela's constructs of design abduction. First, we compare the constructs in RID and in design abduction. Then, we map each RID phase to design abduction constructs.

\subsection{Constructs in RID and Kroll and Koskela's abductive design}

First, we compare the constructs in RID and Kroll and Koskela's Abductive Design. Kroll and Koskela use four constructs: function, mode of action, way of use and form/artefact. We find remarkable correspondence with some of RID's concepts. However, the constructs used in RID differ in the Problem design and Solution design stages. Table 2 and Table 3 show the mapping for (respectively) RID's Problem setting (Knowledge design and Problem design separately) and RID's Problem solving (Solution design and Business design merged together for clarity).

Table 2. Comparing constructs in abductive reasoning and RID's Problem setting

\begin{tabular}{|c|c|c|c|c|}
\hline $\begin{array}{l}\text { Abductive } \\
\text { reasoning }\end{array}$ & $\begin{array}{l}\text { RID Problem } \\
\text { design }\end{array}$ & Comment & $\begin{array}{l}\text { RID Knowledge } \\
\text { design }\end{array}$ & Comment \\
\hline Function & \begin{tabular}{|l|} 
Initial idea, \\
Ideal goal, \\
Value buckets
\end{tabular} & $\begin{array}{l}\text { Inverse formulation: } \\
\text { the artefact should } \\
\text { prevent problems } \\
\text { from happening }\end{array}$ & $\begin{array}{l}\text { Meaningful deep } \\
\text { knowledge for the } \\
\text { project }\end{array}$ & \\
\hline $\begin{array}{l}\text { Mode of } \\
\text { action }\end{array}$ & $\begin{array}{l}\text { Causality of } \\
\text { problems, } \\
\text { Coverage of } \\
\text { solutions }\end{array}$ & $\begin{array}{l}\text { Synthesised in a } \\
\text { causal map of the } \\
\text { influences between } \\
\text { variables }\end{array}$ & $\begin{array}{l}\text { Investigation } \\
\text { strategy }\end{array}$ & $\begin{array}{l}\text { Identify methods } e . g \text {. } \\
\text { observation, } \\
\text { interviews }\end{array}$ \\
\hline Way of use & $\begin{array}{l}\text { Activity fields, } \\
\text { Archetypal usage } \\
\text { scenarios }\end{array}$ & $\begin{array}{l}\text { Broad situations to } \\
\text { be investigated } \\
\text { Represent current } \\
\text { usages }\end{array}$ & Investigation plan & $\begin{array}{l}\text { Identifies who does } \\
\text { what, when, and how }\end{array}$ \\
\hline Artefact & Existing solutions & & Books of knowledge & \\
\hline
\end{tabular}

During RID's Problem setting, abductive reasoning constructs correspond to RID concepts that describe how the world currently is. They do not refer to new propositions but rather to an in-depth exploration of how people act, what problems they experience and what solutions exist to solve them. During RID's Problem solving, the correspondence between abductive reasoning constructs and RID constructs is more direct, since the Solution design process aims to define a new artefact.

Table 3. Comparing constructs in abductive reasoning and RID's Problem solving

\begin{tabular}{l|l|l}
$\begin{array}{l}\text { Abductive } \\
\text { reasoning }\end{array}$ & RID Problem solving & Comment \\
\hline Function & Ambition perimeter & $\begin{array}{l}\text { A set of user problems to be alleviated in identified } \\
\text { usage situations } \\
\text { Technological and physical principles of the } \\
\text { solution } \\
\text { Proposed usage scenarios }\end{array}$ \\
Way of use & $\begin{array}{l}\text { Solution principles } \\
\text { Designed Usage scenarios, } \\
\text { Ausiness model } \\
\text { (innovative chosen) solution }\end{array}$ & $\begin{array}{l}\text { Proposed way of sending solution to the market } \\
\text { All combinations of product-service are possible } \\
\text { (not only products) }\end{array}$
\end{tabular}

\subsection{Design in the first RID stage - Problem and Knowledge Design}

\subsubsection{Mapping the processes}

Figure 3 maps the Problem design process of RID in the domains of the abductive design model of Kroll and Koskela. Differences appear clearly. Abductive reasoning starts from the function, then infers the mode of action and the way of use, and finally infers the form of the artefact. RID's Problem design 
starts from the way of use (after the reframing of the initial idea) and ends with elements of function and value. One may therefore wonder if this RID stage is indeed a design stage.

In more details, RID's Problem design starts from an initial idea that can be either an artefact (intuition of a new product or service), a way of use (intuition of a new usage), a mode of action (a new technology), or value/function (new function of value to fulfil. Then this initial idea defines activity fields, considered as a way of use. These activity fields allow defining the ideal goal (value/function), but also defining a legitimate perimeter of innovation and thus usage scenarios (way of use), existing solutions (artefact) and problems and their causality (mode of action) to study. The association of existing solutions on one hand and usage scenarios, causality of problems and coverage of solutions on the other hand, ensures the identification of value buckets and an ambition perimeter thanks to the DSMValue bucket algorithm (Yannou et al., 2016) in a deductive scheme.

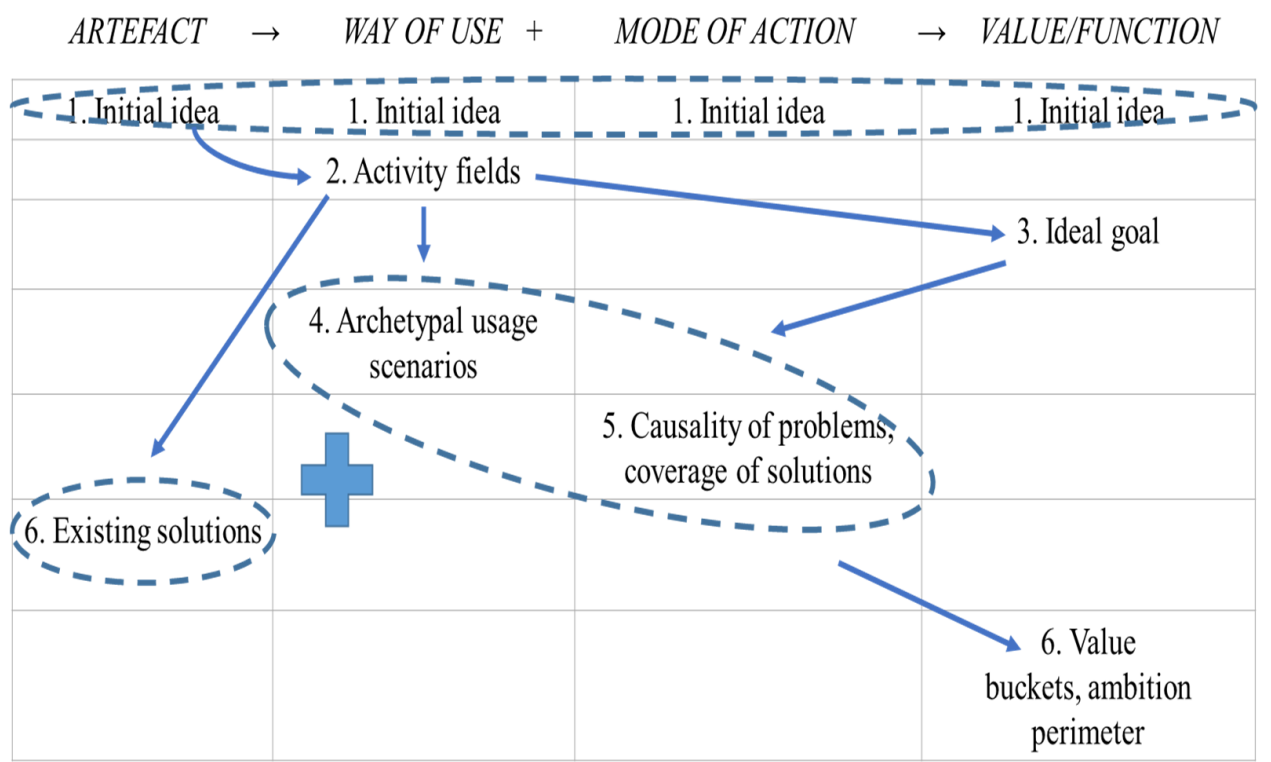

Figure 3. Comparing RID's Problem Design process to the abductive design process

Figure 4 maps the Knowledge design process of RID in the domains of the abductive design model of Kroll and Koskela. The correspondence appears clearly. Designers have to build a project organisation to acquire the knowledge they need for the project. This entails the identification of knowledge gaps (value/function) from the activity fields, then the definition of an investigation strategy (where appropriate data collection methods are selected from a predefined list of common strategies) and of an investigation plan (which specifies how to implement the investigation strategy), which leads to a data collection process and the edition of books of knowledge (artefacts).

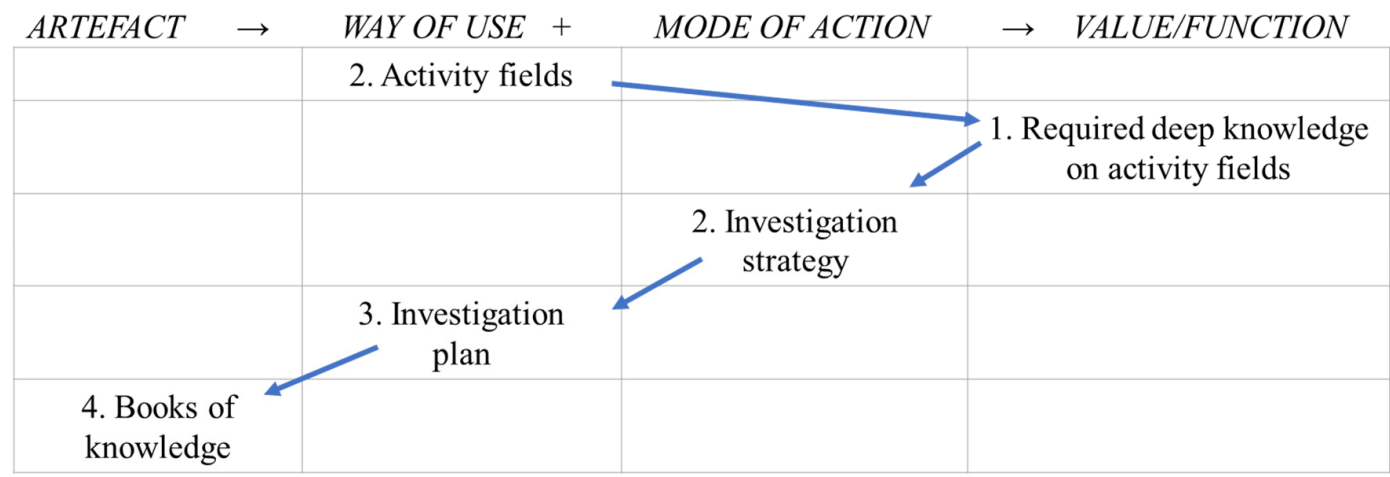

Figure 4. Comparing RID's Knowledge Design process to the abductive design process 


\subsubsection{Analysis}

In the first stage of RID, designers gather (Knowledge Design) and process (Problem Design) information. Most of the activity focuses on how things happen today and what problems arise in today's world, rather than on what and how to change things tomorrow. Designers observe and document usages, users' problems and the performance of existing solutions. They then process this information to identify areas where improvements are most needed. The question is: is this design? Cross (2001) reminds us that "What designers especially know about is the "artificial world"- the human-made world of artefacts. What they especially know how to do is the proposing of additions to and changes to the artificial world." To manage this, "design begins with a function, a need to be satisfied, and terminates with form, a description of a proposed artefact" (Kroll and Koskela, 2016).

Is there an artefact in the Problem design stage of RID, do designers add new objects to the world in this stage? The process seems to be actually more a representation and categorization process. Designers explore a perimeter and acquire information on the events that happen inside of it, the causal structure that links them and the intrication between situations and events. Based on this information, they decide to focus on some proved unmet problems of importance rather than on supposedly expressed needs. The projection of Problem design in the abductive design process reveals an atypical logical reasoning process in the first steps (from the initial idea to the identification of the solutions (6.), usages (4.) and problems (5.) to study) that tends to be close to an abductive scheme, as steps 4,5 and 6 are driven by the definition of the ideal goal (3.) classified as value/function. The second part of Problem design is clearly a deductive process that leads to the definition of an ambition perimeter (a subset of value buckets), that are themselves the starting point of the two-step innovative abduction process of RID's Problem solving (see next section).

When it comes to the Knowledge design process, a design approach can be identified in the way designers specify, plan and carry out the investigation. They identify requirements (what do we not know, that would be useful for the project?), select appropriate strategies to meet these requirements (which investigation approaches could help us get this knowledge?), plan the actual investigation (who will do what, when?) and finally deliver books of knowledge. The logical reasoning process is here more a two-step selective abduction process as investigation strategies (mode of action) are known (there is a predefined list of investigation strategies

The products of the Problem setting stage are:

- Books of knowledge, where designers order and store the information they have gathered, and the ambition perimeter, which is the result of an optimization.

- Models of usages, of the causal mechanisms generating users' problems, and of the usage coverage and performance of existing solutions.

- An ambition perimeter, which is defined from the results of the DSM Value Bucket algorithm.

The first two elements, knowledge books and models, provide descriptive and explanatory knowledge of today's world. When it comes to the ambition perimeter, it is the result of an optimization process, since the DSM Value Bucket identifies the pairs (usage situation, users' pain) with the most important problems for which the performance of existing solutions is weak while occurring in frequent usage situations. The algorithm aggregates and orders knowledge, it does not add new elements to the world. Overall, these processes are modelling processes rather than design processes per se. However, the investigation process in Knowledge design is a design process: it starts with a need (synthetic, usable synthesis of the deep knowledge required in the project) and delivers books of knowledge, artefacts that embody the required value.

Through the combined processes of Knowledge design and Problem design, designers define a sensible concept to explore in further stages. We understand concept in the sense of C-K theory, i.e. a proposition defining an element which we know does not exist in the world today, but which we don't know if we can produce it (Hatchuel and Weil, 2009). In this case, the concept is expressed as

A system that addresses important users' problems $p 1 \ldots p N$ in frequent related usage situations $s 1 \ldots s N$ sufficiently outperforming that of any existing solution.

Designers have normally identified all existing solutions in their knowledge exploration during Problem Design, so no existing artefact can fill these conditions. However, at this stage designers don't know if a 
system that fills these conditions exists. Given these observations, the Problem Design sub-process is one of "knowledge processing and ordering". It starts from a set of activity fields, and through the collection of data and the organisation of knowledge, it defines a concept (a $\mathrm{K} \rightarrow \mathrm{C}$ operation in $\mathrm{C}-\mathrm{K}$ theory).

\subsection{Design in the second RID stage - Problem solving}

\subsubsection{Mapping the process}

Figure 5 maps the Problem solving process of RID in the domains of the abductive design model of Kroll and Koskela. The RID process corresponds to a two-step abduction: designers start from functions to perform, the ambition perimeter being a set of selected value buckets, a value bucket being considered as a function "remove or diminish this problem during this usage situation". Then, designers generate designed usage scenarios, which correspond to the way of use of the system in an improved world where value buckets have been processed. They then define a concept, which is a set of coordinated working principles that together can produce the desired function in the defined usage scenario. From this concept, they can develop an artefact.

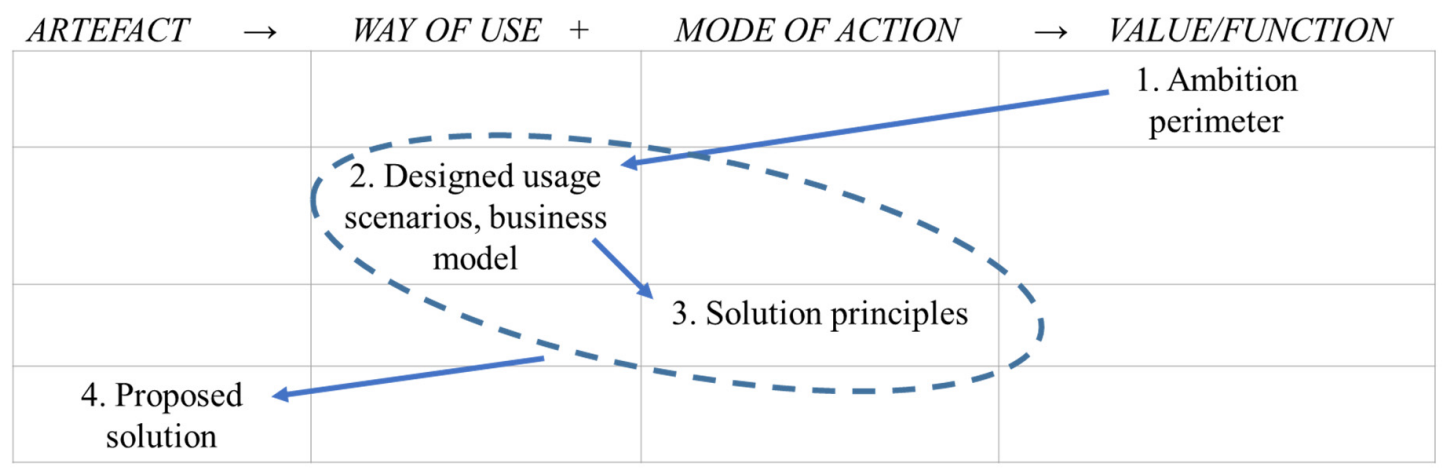

Figure 5. Comparing RID's Solution Design phase to the abductive design process

\subsubsection{Analysis}

What remains to be determined is the type of abduction that is performed in this stage. In selective abduction, designers identify a suitable concept in their "repertoire" which they know to produce the desired function. They then design an artefact that uses this concept. In innovative abduction, designers have to come up with a concept that can create the desired function.

In the case of RID's Solution Design process, designers have identified a repertoire of principles during the Problem Setting stage, that can then be complemented at this stage. They then assemble some of these principles in innovative ways into a concept that can produce the desired function. The process is more innovative abduction than selective abduction, because a new concept has to be defined. This way of working somehow reminds of the way TRIZ and ASIT work. A knowledge base is built during Problem Design, which contains potential working principles. During Solution Design, designers work in a close world inside this knowledge base (Reich et al., 2012).

\section{Conclusion}

Findings are coherent with what RID claims: a first phase to capture a rich understanding of the current situation, then a design phase to generate new objects that can improve the situation. They show that the first phase of RID, Problem setting, departs from the model of two-step innovative abduction, while the Problem solving phase closely resembles the model. Figure 6 synthesizes these findings. RID supports design reasoning through:

- A first Problem setting stage that

- Gives designers the required knowledge to perform design in the domain (Knowledge design) in a two-step selective abduction reasoning that synthesises the required knowledge in an easy to communicate format; 
- Helps designers identify areas where value creation can be maximal through solving useful issues (see the definition of usefulness in Bekhradi et al., 2015), thus providing the starting seeds for ideation in Problem Design in an abductive, then deductive logical reasoning.

- A Solution design process that supports directly two-step innovative abduction, where

$\circ$ Designers define new usages that can provide the expected value, and then

- Designers propose concepts that embody original combinations of working principles identified in Problem Design.

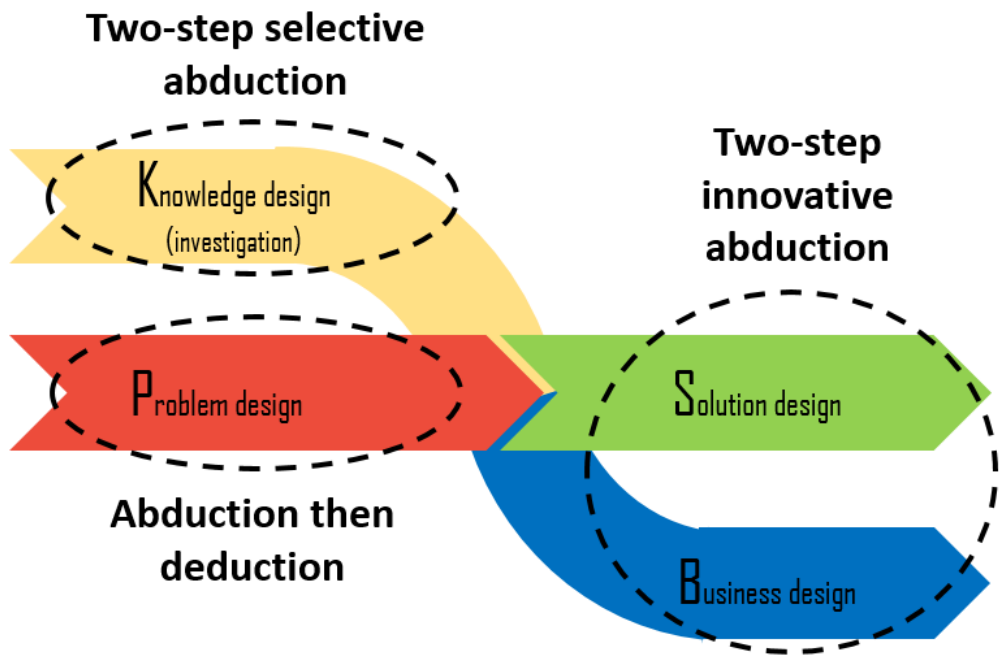

Figure 6. Synthesis of RID's main logical reasonings

Our analysis highlights the need for a well-managed investigation and analysis in RID's Problem Design. To enable radically new solutions to emerge in Solution Design, designers have to properly abstract solution principles during Problem Design. This way they can create a repertoire of working principles from which they can assemble a concept during Solution Design. This finding matches empirical results which show correlations between the quality of Problem Design and the quality of Solution Design (Yannou et al., 2013a). When it comes to models of design, this would mandate more research on how designers identify functions that are worth producing and that create real value for customers.

To complete this analysis, we plan to analyse RID using other formal models of design, such as the Function-Behaviour-Structure framework or C-K theory.

\section{References}

Bekhradi, A., Yannou, B. and Cluzel, F. (2016), "Importance of Problem Setting Before Developing a Business Model Canvas", Proceedings of DESIGN 2016 / the 14th International Design Conference, Dubrovnik, Croatia, May 16-19, 2016, The Design Society, Glasgow, pp. 907-916.

Bekhradi, A., Yannou, B., Cluzel, F. and Vallette, T. (2017), "Categorizing user pains, usage situations and existing solutions in front end of innovation: The case of smart lighting project", Proceedings of the 21st International Conference on Engineering Design (ICED'17), Vol. 4, Vancouver, Canada, August 21-25, 2017, The Design Society, Glasgow, pp. 533-542.

Bekhradi, A., Yannou, B., Farel, R., Zimmer, B. and Chandra, J. (2015), "Usefulness Simulation of Design Concepts", Journal of Mechanical Design, Vol. 137 No. 7, pp. 071414. https://doi.org/10.1115/1.4030180

Christensen, C.M. (1997), The innovator's dilemma: when new technologies cause great firms to fail, The management of innovation and change series, Harvard Business School Press, Boston, MA.

Christensen, C.M., Hall, T., Dillon, K. and Duncan, D.S. (2016), "Know your customers' "jobs to be done"', Harvard Business Review, Vol. 9, pp. 54-62.

Cooper, R.G. (1990), "Stage-gate systems: A new tool for managing new products", Business Horizons, Vol. 33 No. 3, pp. 44-54. https://doi.org/10.1016/0007-6813(90)90040-I

Cross, N. (1982), "Designerly ways of knowing", Design Studies, Vol. 3 No. 4, pp. 221-227. https://doi.org/10.1016/0142-694X(82)90040-0 
Cross, N. (2001), "Designerly Ways of Knowing: Design Discipline Versus Design Science”, Design Issues, Vol. 17 No. 3, pp. 49-55. https://doi.org/10.1162/074793601750357196

Dorst, K. (2011), “The core of 'design thinking' and its application”, Design Studies, Vol. 32 No. 6, pp. 521-532. https://doi.org/10.1016/j.destud.2011.07.006

Gero, J.S. and Kannengiesser, U. (2004), "The situated function-behaviour-structure framework", Design Studies, Vol. 25 No. 4, pp. 373-391. https://doi.org/10.1016/j.destud.2003.10.010

Hatchuel, A. and Weil, B. (2009), "C-K design theory: an advanced formulation", Research in Engineering Design, Vol. 19 No. 4, pp. 181-192. https://doi.org/10.1007/s00163-008-0043-4

Jaruzelski, B., Staack, V. and Goehle, B. (2014), Proven paths to innovation success. [online] Strategy+Business, Strategy\&. Available at: https://www.strategyand.pwc.com/media/file/Proven-Paths-to-InnovationSuccess.pdf

Kim, W.C. and Mauborgne, R. (2015), Blue ocean strategy: how to create uncontested market space and make the competition irrelevant, expanded ed., Harvard Business Review Press, Boston, MA.

Kroll, E. and Koskela, L. (2016), "Explicating concepts in reasoning from function to form by two-step innovative abductions", Artificial Intelligence for Engineering Design, Analysis and Manufacturing, Vol. 30 No. 2, pp. 125-137. https://doi.org/10.1017/S0890060416000020

Lamé, G., Yannou, B. and Cluzel, F. (2018), "Usage-driven problem design for radical innovation in healthcare", BMJ Innovations, Vol. 4 No. 1, pp. 15-23. https://doi.org/10.1136/bmjinnov-2016-000149

Osterwalder, A. and Pigneur, Y. (2010), Business model generation: a handbook for visionaries, game changers, and challengers, Wiley, Hoboken, New Jersey.

Reich, Y., Hatchuel, A., Shai, O. and Subrahmanian, E. (2012), "A theoretical analysis of creativity methods in engineering design: casting and improving ASIT within C-K theory", Journal of Engineering Design, Vol. 23 No. 2, pp. 137-158. https://doi.org/10.1080/09544828.2010.493505

Sobek II, D.K., Ward, A.C. and Liker, J.K. (1999), “Toyota's principles of set-based, concurrent engineering”, Sloan Management Review, Vol. 40 No. 2, pp. 67-83.

Yannou, B. (2015), "Supporting need seeker innovation: the Radical Innovation Design methodology", Proceedings of 20th International Conference on Engineering Design (ICED'15), Vol. 8, Milan, Italy, July 2730, 2015, The Design Society, Glasgow, pp. 51-60.

Yannou, B., Cluzel, F. and Farel, R. (2016), "Capturing the relevant problems leading to pain- and usage-driven innovations: The Dependency Structure Modeling Value Bucket algorithm”, Concurrent Engineering Research and Applications, (online first). https://doi.org/10.1177/1063293X16666311

Yannou, B., Jankovic, M., Leroy, Y. and Kremer, G.E.O. (2013a), "Observations From Radical Innovation Projects Considering the Company Context”, Journal of Mechanical Design, Vol. 135 No. 2, pp. 021005. https://doi.org/10.1115/1.4023150

Yannou, B., Yvars, P.-A., Hoyle, C. and Chen, W. (2013b), "Set-based design by simulation of usage scenario coverage", Journal of Engineering Design, Vol. 24 No. 8, pp. 575-603. https://doi.org/10.1080/09544828.2013.780201

Dr. François Cluzel, Assistant professor

CentraleSupélec, Laboratoire Genie Industriel

3 rue Joliot-Curie, 91190 Gif-sur-Yvette, France

Email: francois.cluzel@centralesupelec.fr 